\title{
Ultrasonography Measurement of Abdominal Subcutaneous Fat Thickness and Its Correlation with Hyperlipidemia and Steatohepatitis in Obese People
}

\author{
Dr. Roshani Pathak ${ }^{* 1}$, Sunil Pradhan ${ }^{2}$, Abhushan Tuladhar ${ }^{3}$, Amit Shrestha ${ }^{4}$, Riwaz Acharya ${ }^{5}$ \\ ${ }^{1}$ Lecturer, Department of Radiology, Nepal Medical College and Teaching Hospital, Jorpati, Nepal \\ ${ }^{2}$ Professor, Department of Radiology, Nepal Medical College and Teaching Hospital, Jorpati, Nepal \\ ${ }^{3}$ Associate Professor, Department of Radiology, Nepal Medical College and Teaching Hospital, Jorpati, Nepal \\ ${ }^{4}$ Associate Professor, Department of Radiology, Nepal Medical College and Teaching Hospital, Jorpati, Nepal \\ ${ }^{5}$ Lecturer, Department of Radiology, Nepal Medical College and Teaching Hospital, Jorpati, Nepal
}

\section{Address for Correspondence}

\section{Dr. Roshani Pathak}

Lecturer, Department of Radiology,

Nepal Medical College and Teaching Hospital, Jorpati, Nepal

\section{Introduction}

Unhealthy dietary practices, sedentary lifestyle and obesity have emerged as major risk factors of Non communicable diseases (NCD) ${ }^{[1]}$ In India there is shift in dietary patterns to more 'Western' diets rich in saturated fat, refined foods and sugar and low in fibre ${ }^{[2]}$ due to which there is a higher prevalence of traditional cardiovascular disease risk factors such as obesity, physical inactivity, tobacco use and high intake of saturated fat. ${ }^{[3]}$ In 2000, the International Obesity Task Force of the WHO (IOTFWHO) proposed a modification of National Heart, Lung, and Blood Institute guidelines on overweight/obesity which is as follows : Overweight, 23 to $<25$; class I obesity, 25 to $<30$; and class II obesity, $\geq 30$. Redefining the obesity cut-off (BMI >25) creates an "obesity burden" in urban India. ${ }^{[4]}$

World Health Organization in 2011, reported that the prevalence of obesity has doubled in the last 3 decades. ${ }^{[5]}$ The prevalence of obesity in India is continuously increasing and data shows that around $13 \%$ to $50 \%$ of the urban population and $8 \%-38.2 \%$ of the rural population is suffering from obesity. Obesity is common in women as compared to men. ${ }^{[6]}$ Also there is increase in the childhood obesity which can cause many complications such as hyperlipidemia and steatohepatitis at an early age. It may also lead to obesity in adulthood and thereby result in many lifestyle diseases. ${ }^{[7]}$ Some studies have reported that $28.3 \%$ and $16.7 \%$ of obese children have above normal levels of serum triglycerides and total cholesterol respectively but fatty liver, as a result of obesity, can progress to liver cirrhosis. ${ }^{[8,9]}$ The most common cause of chronic liver disease in adults and children is non-alcoholic fatty liver disease (NAFLD). In adults the prevalence of NAFLD ranges from $17 \%$ to $33 \%,{ }^{[1]}$ whereas in children, it ranges from $2.6 \%$ to $9.6 \%$, and from $22.5 \%$ to $44 \%$ in children with obesity. ${ }^{[10,11]}$ The presentation of NAFLD may vary from simple liver steatosis to non-alcoholic steatohepatitis (NASH), liver cirrhosis and may be hepatocellular carcinoma. ${ }^{[12]}$ The pathogenesis of NAFLD is still a problem with a plethora of implications and potential solutions for clinical practice. Many people are affected by NAFLD and around $60 \%-70 \%$ remain asymptomatic with simple liver steatosis. ${ }^{[13]}$

To measure fat thickness ultrasound was used from mid 1960s. ${ }^{[14]}$ Measurement of the thickness of subcutaneous and visceral fat have been studied by computed tomography, dual-energy X-ray absorptiometry, and abdominal ultrasonography. ${ }^{[15,16,17]}$ Ultrasonography seems to be used far less than the other methods for body composition assessment, many students and clinicians are not familiar with its usefulness and versatility as a body composition assessment tool.

The aim of this study is to measure the subcutaneous fat in obese persons and review of ultrasound technology is to explain the technical principles of the method and measurement procedures

\section{Material and Methods}

This prospective study was carried out at Nepal Medical College and Teaching Hospital Jorpati, Kathmandu in Department of Radiology. Total of 200 patients were included in the study. The BMI of the entire subject was calculated using their weight and height. BMI above the 95 th percentile was defined as obese. Serum lipid profile and liver amino transferase levels were measured of all the participants included in the study.

Technical principle of ultrasonography- Sound travels in the form of a cyclical wave and human body can detect sound with a frequency of about 20 to $20,000 \mathrm{~Hz}$. Pulses of ultrasound are produced by Piezoelectric crystals in the transducer of the scan head. Beam of ultrasound is transmitted through the skin. When the ultrasound beam comes in contact with any tissue interface i.e. skin-subcutaneous fat, fat muscle and muscle bone, it is partially 


\section{International Journal of Innovative Research in Medical Science (IJIRMS) \\ Volume 03 Issue 12 Dec 2018, ISSN: 2455-8737, Imp. Factor - 4.102 \\ Available online at $-\underline{w w w . i j i r m s . i n}$}

reflected back to the transducer as an echo. The transducer has a dual function of transmitting the ultrasound and receiving it. The echoes are converted into signals for processing by the transducer. The strength of each reflected wave is represented by a dot and the position of the dot represents the depth from which the echo was received. The dots are combined to form an image. Thus the principle of ultrasound imaging is reflection of ultrasound waves from tissue in the path of the beam. The amount of sound reflected is dependent on the changes in acoustic impedance between two tissue interfaces. Fat and muscle have impedances of $0.138 \mathrm{~g} \cdot \mathrm{cm}^{-} 1 \cdot \mathrm{s}^{-} 1$ and $0.170 \mathrm{~g} \cdot \mathrm{cm}^{-} 1 \cdot \mathrm{s}^{-} 1$, respectively while bone has a relatively high impedance of $0.78 \mathrm{~g} \cdot \mathrm{cm}^{-} 1.1010$

Procedure of ultrasound- Gel is placed on the head of the transducer and/or the skin at the site to be measured. Abdominal subcutaneous fat thickness was measured in the supine position during normal respiration with minimal pressure applied by the US probe. Midline abdominal subcutaneous fat thickness (MASFT) was measured transversely at about one $\mathrm{cm}$ caudal to the umbilicus level and the right flank abdominal subcutaneous fat thickness (RFASFT) was measured coronally at two locations of the right flank with the average value being recorded.

To diagnosis the Hepatic steatosis ultrasonography was done. A 6.0 $\mathrm{MHz}$ probe was used to look for the echogenicity of the liver in the diagnosis of hepatic steatosis. Suspected steatosis was graded as

Grade I (mild): slight diffuse increase in the fine echoes in the hepatic parenchyma with normal visualization of the diaphragm and intra hepatic vessel borders.

Grade II (moderate): moderate diffuse increase in the fine echoes with slightly impaired visualization of the intra hepatic vessels and diaphragm.

Grade III (severe): marked increase in fine echoes with poor or non visualization of the intra hepatic vessel borders, diaphragm, and posterior portion of the right lobe of the liver.

\section{Results and Observations}

A total of 200 people were included in the study of which 90 were male and 110 were female. Average age of participants was $38 \pm 16.8$ (mean \pm standard deviation). Mean age of male was $35 \pm 21.4$ and that of females was $39 \pm 15.7$. Mean weight was $61 \pm 14$.4. Mean weight of males was $64 \pm 11.4$ and females was $56 \pm 12$.6. Mean height in $\mathrm{cm}$ was $154 \pm 5$.2. Mean height of males was $159 \pm 9.6$ and females was $142 \pm 6.4$. Mean BMI of total patient was $27 \pm 4.3$. Mean BMI of males was $27 \pm 3.4$ and females was $28 \pm 4$.6. As compared to males BMI of females was higher.

Table 1: Age, Sex, Weight, Height and BMI of participants

\begin{tabular}{|l|c|c|c|c|c|c|c|}
\hline & $\mathbf{N = 2 0 0}$ & MALE & FEMALE & Standard error & $\mathbf{9 5 \%}$ CI & t-statistic & Significance level \\
\hline Age & $38 \pm 16.8$ & $35 \pm 21.4$ & $39 \pm 15.7$ & 1.877 & 0.3104 to 7.6896 & 2.131 & $\mathrm{P}=0.0337$ \\
\hline Sex & $110 \mathrm{~F} / 90 \mathrm{M}$ & 90 & 110 & & & & \\
\hline Weight $(\mathbf{k g})$ & $61 \pm 14.4$ & $64 \pm 11.4$ & $56 \pm 12.6$ & 1.201 & -10.3621 to -5.6379 & -6.658 & $\mathrm{P}<0.0001$ \\
\hline Height $(\mathbf{c m})$ & $154 \pm 5.2$ & $159 \pm 9.6$ & $142 \pm 6.4$ & 0.816 & -18.6039 to -15.3961 & -20.837 & $\mathrm{P}<0.0001$ \\
\hline BMI & $27 \pm 4.3$ & $27 \pm 3.4$ & $28 \pm 4.6$ & 0.404 & 0.2048 to 1.7952 & 2.472 & $\mathrm{P}=0.0138$ \\
\hline
\end{tabular}

Values are presented as mean \pm standard deviation.

Table 2: Serum cholesterol and Liver profile

\begin{tabular}{|l|c|c|c|c|c|c|c|}
\hline \multicolumn{1}{|c|}{ S size } & $\mathbf{2 0 0}$ & Male & Female & Standard error & $\mathbf{9 5 \%}$ CI & t-statistic & Significance level \\
\hline Tot Cholesterol & $187 \pm 24.7$ & $189 \pm 22.5$ & $176 \pm 19.4$ & 2.101 & -17.1299 to -8.8701 & -6.188 & $\mathrm{P}<0.0001$ \\
\hline TG & $141.5 \pm 88.8$ & $159 \pm 56.7$ & $139 \pm 77.4$ & 6.784 & -33.3378 to -6.6622 & -2.948 & $\mathrm{P}=0.0034$ \\
\hline HDL & $48.4 \pm 11.4$ & $49 \pm 10.5$ & $46 \pm 9.8$ & 1.016 & -4.9966 to -1.0034 & -2.954 & $\mathrm{P}=0.0033$ \\
\hline LDL & $101.0 \pm 32.7$ & $102 \pm 29.4$ & $96 \pm 22.5$ & 2.618 & -11.1465 to -0.8535 & -2.292 & $\mathrm{P}=0.0224$ \\
\hline AST & $41.7 \pm 29.7$ & $43 \pm 29.8$ & $40.5 \pm 27.4$ & 2.863 & -8.1275 to 3.1275 & -0.873 & $\mathrm{P}=0.3830$ \\
\hline ALT & $58.4 \pm 61.4$ & $59.7 \pm 67.5$ & $55.4 \pm 52.1$ & 6.029 & -16.1534 to 7.5534 & -0.713 & $\mathrm{P}=0.4762$ \\
\hline
\end{tabular}

TG: triglyceride, HDL: high density lipoprotein, LDL: low density lipoprotein, AST: aspartate aminotransferase, ALT: alanine aminotransferase.

Total serum cholesterol, triglyceride, high density lipoprotein and low density lipoprotein was $187 \pm 24.7,141.5 \pm 88.8,48.4 \pm 11.4,101.0 \pm 32.7$ respectively while AST and ALT was $41.7 \pm 29.7,58.4 \pm 61.4$ respectively.

Table 3: Hepatic steatosis and grading

\begin{tabular}{|l|c|c|c|c|c|c|}
\hline hepatic steatosis & Total $\mathbf{n = 2 0 0}$ & Male n=90 & Female $\mathbf{n = 1 1 0}$ & $\mathbf{9 5 \%}$ CI & Chi-squared & Significance level \\
\hline Normal & $73(36.5 \%)$ & $32(43.84 \%)$ & $41(56.16 \%)$ & -3.8112 to 27.5802 & 2.201 & $\mathrm{P}=0.1379$ \\
\hline Grade I & $54(27 \%)$ & $21(38.89 \%)$ & $33(61.11 \%)$ & 3.3787 to 38.9743 & 5.283 & $\mathrm{P}=0.0215$ \\
\hline Grade II & $66(33 \%)$ & $37(56.06 \%)$ & $29(43.94 \%)$ & -4.8194 to 28.1166 & 1.924 & $\mathrm{P}=0.1654$ \\
\hline Grade III & $7(3.5 \%)$ & $4(57.14 \%)$ & $3(42.86 \%)$ & -31.1108 to 52.5151 & 0.265 & $\mathrm{P}=0.6066$ \\
\hline
\end{tabular}

Of the total 200 patients 54 (27\%) were observed with grade I hepatic steatosis, while 66 (33\%) and 7 (3.5\%) were grade II and grade III respectively. 
International Journal of Innovative Research in Medical Science (IJIRMS)

Volume 03 Issue 12 Dec 2018, ISSN: 2455-8737, Imp. Factor - 4.102

Available online at $-\underline{w w w . i j i r m s . i n}$

Table 4: Midline Abdominal Subcutaneous Fat Thickness, Right Flank Abdominal Subcutaneous Fat Thickness and Grade of Hepatic Steatosis

\begin{tabular}{|l|c|c|}
\hline Grade of hepatic steatosis & MASFT in $\mathbf{~ c m}$ & RFASFT in cm \\
\hline Normal n=73 & $2.1 \pm 0.6$ & $1.6 \pm 0.4$ \\
\hline Grade I & $3.2 \pm 0.5$ & $2.1 \pm 0.5$ \\
\hline Grade II & $3.6 \pm 0.6$ & $2.5 \pm 0.7$ \\
\hline Grade III & $4.3 \pm 0.7$ & $3.0 \pm 0.8$ \\
\hline
\end{tabular}

MASFT: midline abdominal subcutaneous fat thickness, RFASFT: right flank abdominal subcutaneous fat thickness.

Midline Abdominal Subcutaneous Fat Thickness (MASFT) in normal was 2.1 \pm 0.6 , while in Grade I, Grade II and in Grade III was $3.2 \pm 0.5,3.6 \pm 0.6$ and $4.3 \pm 0.7$ respectively. Right flank abdominal subcutaneous fat thickness (RFASFT) in normal, Grade I, Grade II and in Grade III was $1.6 \pm 0.4,2.1 \pm 0.5,2.5 \pm 0.7$ and $3.0 \pm 0.8$ respectively. Statistically significant correlation was observed between MASFT and the grade of hepatic steatosis $(\mathrm{p}=0.000)$. RFASFT also had a statistically significant correlation with the grade of hepatic steatosis $(\mathrm{p}<0.001)$.

\section{Discussion}

During this early period of late 1960s through mid-1980s, there were different opinions as to which method, ultrasound or skinfold, best measured subcutaneous fat. Sloan in his studies in 1967 compared seven skinfold site to ultrasound measures taken at the same locations and to densitometry from underwater weighing. ${ }^{[18]}$ Fanelli and Kuczmarski was suggested that ultrasound was equal to skinfolds for predicting body fat. ${ }^{[19]}$ Leahy et al. ${ }^{[20]}$ in 2012 observed that a single ultrasound measure of subcutaneous adipose tissue at the abdomen was highly correlated with body fat percentage.

Recent studies suggest that ultrasound is a reliable, and fast method for assessing both subcutaneous and visceral adipose compartments. Bazzocchi et al. ${ }^{[21]}$ shown the relationships between computed tomography (CT) and ultrasound measures of visceral and subcutaneous parameters. There are many advantages to determine the subcutaneous fat by ultrasound but there are some disadvantages like fascia could be mistaken for the boundary layer between subcutaneous fat and muscle or pressing the transducer onto the patients skin with greater force will significantly reduce the subcutaneous fat thickness. ${ }^{[22]}$

To detect Steatosis ultrasonography can be a accurate tool to diagnose the condition in early stages when serum AST, ALT levels are normal. In our study MASFT $>4.0$ suggest the severe hepatic steatosis while $<2$ was seen in normal individuals. Also RFASFT $>3.0$ suggest the severe hepatic steatosis while $<1.6$ was seen in normal individuals. Eifler ${ }^{[23]}$ in his study shown that For women, visceral fat thickness $\geq 7 \mathrm{~cm}$ suggests the presence of mild steatosis; and $\geq 9 \mathrm{~cm}$ suggests moderate to severe steatosis with risk for steatohepatitis and metabolic syndrome. For men, visceral fat thickness $\geq 8 \mathrm{~cm}$ suggests the presence of mild steatosis; and $\geq$ $10 \mathrm{~cm}$, suggests moderate to severe steatosis with risk for steatohepatitis and metabolic syndrome. While Leite et al., investigated the correlation between visceral fat thickness and cardiovascular risk. His study has indicated a cut-off value of $7 \mathrm{~cm}$ to predict a moderate cardiovascular risk for both female and male individuals. ${ }^{[24]}$ In our study no statistically significant difference was observed in subcutaneous fat thickness between male and female individuals, age groups and in relation to the presence or not of steatosis but statistical significant difference was observed in serum cholesterol levels of men and women.

\section{Conclusion}

Our study demonstrated the correlation between steatosis and subcutaneous fat thickness measured by ultrasonography and values were suggested for normality and risk for hepatic steatosis for both male and female individuals. So it is suggested that subcutaneous fat measurement should be included in the routine abdominal ultrasonography studies as a predictor of hepatic steatosis and metabolic syndrome

\section{References}

[1] WHO | Diet and physical activity: a public health priority [Internet]. World Health Organization;. Available from: http://www.who.int/dietphysicalactivity/background/en/.

[2] Shetty PS. Nutrition transition in India.Public Health Nutr. 2002 Feb; 5(1A):175-82.

[3] Singh RB, Pella D, Mechirova V, Kartikey K, Demeester F, Tomar RS, Beegom R, Mehta AS, Gupta SB, De Amit K, Neki NS, Haque M, Nayse J, Singh S, Thakur AS, Rastogi SS, Singh K, Krishna A, Five City Study Group. Prevalence of obesity, physical inactivity and undernutrition, a triple burden of diseases during transition in a developing economy. The Five City Study Group.ActaCardiol. 2007 Apr; 62(2):119-27

[4] Anuurad E, Shiwaku K, Nogi A, Kitajima K, Enkhmaa B, Shimono K, Yamane Y. The new BMI criteria for asians by the regional office for the western pacific region of WHO are suitable for screening of overweight to prevent metabolic syndrome in elder Japanese workers.J Occup Health. 2003 Nov; 45(6):335-43.

[5] World Health Organization. Global status report on noncommunicable diseases 2010. Geneva: World Health Organization; 2011. pp. 22-31.

[6] Misra A., Shrivastava U. Obesity and dyslipidemia in South Asians. Nutrients. 2013;5(July (7)):2708-2733

[7] Pulgaron ER, Delamater AM. Obesity and type 2 diabetes in children: epidemiology and treatment.CurrDiab Rep. 2014 Aug; 14(8):508.

[8] Lee HH, Choi SK, Seo JS. Obesity index and related factors among elementary school students visiting pediatric department of general hospital. J Korean Diet Assoc. 2012;18:186-199.

[9] Mathur P, Das MK, Arora NK. Non-alcoholic fatty liver disease and childhood obesity. Indian J Pediatr. 2007 Apr; 74(4):401-7.

[10] Cho Y, Tokuhara D, Morikawa H, Kuwae Y, Hayashi E, Hirose M, Hamazaki T, Tanaka A, Kawamura T, Kawada N, Shintaku H. Transient Elastography-Based 
Liver Profiles in a Hospital-Based Pediatric Population in Japan.PLoS One. 2015; 10(9):e0137239.

[11] Bang KB, Cho YK. Comorbidities and Metabolic Derangement of NAFLD.J Lifestyle Med. 2015 Mar; 5(1):7-13.

[12] Smits MM, Ioannou GN, Boyko EJ, Utzschneider KM. Non-alcoholic fatty liver disease as an independent manifestation of the metabolic syndrome: results of a US national survey in three ethnic groups.J Gastroenterol Hepatol. 2013 Apr; 28(4):664-70.

[13] Ekstedt M, Franzén LE, Mathiesen UL, Thorelius L, Holmqvist M, Bodemar G, Kechagias S. Long-term follow-up of patients with NAFLD and elevated liver enzymes.Hepatology. 2006 Oct; 44(4):865-73.

[14] Booth RA, Goddard BA, Paton A. Measurement of fat thickness in man: a comparison of ultrasound, Harpenden calipers and electrical conductivity.Br J Nutr. 1966; 20(4):719-25.

[15] Schlecht I, Wiggermann P, Behrens G, Fischer B, Koch M, Freese J, Rubin D, Nöthlings U, Stroszczynski C, Leitzmann MF. Reproducibility and validity of ultrasound for the measurement of visceral and subcutaneous adipose tissues. Metabolism. 2014 Dec; 63(12):1512-9.

[16] Wagner DR. Ultrasound as a tool to assess body fat.J Obes. 2013; 2013():280713.

[17] Rothney MP, Catapano AL, Xia J, Wacker WK, Tidone C, Grigore L, Xia Y, Ergun DL. Abdominal visceral fat measurement using dual-energy X-ray: association with cardiometabolic risk factors.Obesity (Silver Spring). 2013 Sep; 21(9):1798-802.

[18] Sloan AW. Estimation of body fat in young men.JAppl Physiol. 1967 Sep; 23(3):311-5.

[19] Fanelli MT, Kuczmarski RJ. Ultrasound as an approach to assessing body composition. Am J ClinNutr. 1984 May; 39(5):703-9.

[20] Leahy S, Toomey C, McCreesh K, O'Neill C, Jakeman P. Ultrasound measurement of subcutaneous adipose tissue thickness accurately predicts total and segmental body fat of young adults.Ultrasound Med Biol. 2012 Jan; 38(1):28-34.

[21] Bazzocchi A, Filonzi G, Ponti F, Sassi C, Salizzoni E, Battista G, Canini R. Accuracy, reproducibility and repeatability of ultrasonography in the assessment of abdominal adiposity. Acad Radiol. 2011 Sep; 18(9):1133-43.

[22] Toomey C, McCreesh K, Leahy S, Jakeman P. Technical considerations for accurate measurement of subcutaneous adipose tissue thickness using B-mode ultrasound. Ultrasound. 2011;19(2):91-96

[23] EIFLER, Roberto Velloso. The role of ultrasonography in the measurement of subcutaneous and visceral fat and its correlation with hepatic steatosis. Radiol Bras, São Paulo, v. 46, n. 5, p. 273-278, Oct. 2013.

[24] Leite CC, Wajchenberg BL, Radominski R, et al. Intraabdominal thickness by ultrasonography to predict risk factors for cardiovascular disease and its correlation with anthropometric measurements. Metabolism. 2002; 51:1034-40. 